\title{
Perfection. Studies in Early Modern France, ed. Anne L. Birberick
}

\author{
Laura Rescia
}

\section{OpenEdition}

\section{Journals}

\section{Edizione digitale}

URL: http://journals.openedition.org/studifrancesi/6603

DOI: 10.4000/studifrancesi.6603

ISSN: 2427-5856

\section{Editore}

Rosenberg \& Sellier

\section{Edizione cartacea}

Data di pubblicazione: 1 septembre 2010

Paginazione: 355-356

ISSN: 0039-2944

\section{Notizia bibliografica digitale}

Laura Rescia, «Perfection. Studies in Early Modern France, ed. Anne L. Birberick», Studi Francesi [Online], 161 (LIV | II) | 2010, online dal 30 novembre 2015, consultato il 08 janvier 2021. URL: http:// journals.openedition.org/studifrancesi/6603 ; DOI: https://doi.org/ERREUR PDO dans /localdata/ www-bin/Core/Core/Db/Db.class.php L.34 : SQLSTATE[HY000] [2006] MySQL server has gone away

Questo documento è stato generato automaticamente il 8 janvier 2021.

\section{(c)}

Studi Francesi è distribuita con Licenza Creative Commons Attribuzione - Non commerciale - Non opere derivate 4.0 Internazionale. 


\title{
Perfection. Studies in Early Modern France, ed. Anne L. Birberick
}

\author{
Laura Rescia
}

\section{NOTIZIA}

Perfection. Studies in Early Modern France, ed. Anne L. BIRBERICK, vol. 12, 2008, pp. XV-217.

1 Sono dieci i contributi raccolti in questo numero tematico di una delle riviste di riferimento dei francesisti nordamericani studiosi del xVII secolo, articoli accomunati dalla scelta del concetto di perfezione come strumento euristico per indagare il discorso seicentesco, in testi e generi diversi. Categoria estetica dominante nell'immaginario collettivo del Grand Siècle, particolarmente pertinente per la Querelle des Anciens et des Modernes, tale nozione si rivela produttiva nello studio della costruzione dell'episteme classicista, il cui carattere contradditorio e dialogico, oggi largamente riconosciuto, è confermato da questi studi. I saggi sono idealmente raggruppabili in quattro diverse sezioni, in cui la perfezione è indagata nel discorso ideologico e politico, in quello morale, nell'estetica teatrale e nella retorica del discorso scientifico. Chloé HOGG, Useful Wounds, pp. 1-25, si concentra sulla semiotica della gloria costruita attraverso lo spettacolo della sofferenza corporea nel regno di Louis XIV. Ricordando Foucault, l'A. evidenzia come tale forma di spettacolarità riattivi il potere: lo conferma l'analisi di pagine di Donneau de Visé, Perrault, Mme de Sévigné sulle ferite di guerra, così come le descrizioni seicentesche del costruendo Hôtel des Invalides. La figura del monarca vi è più simile a quella di un chirurgo che di un taumaturgo, pur sempre riparatore di membra mutilate, e dunque massimamente imperfette, utilizzate nella narrazione come strumento di rinforzo del perfetto assolutismo reale. Louise FRAPPIER, Construction de la figure monarchique et perfection divine dans les récits d'entrée royale à Avignon (1600 et 1622), pp. 26-43 esamina come la sacralità e la perfezione monarchiche si siano costruite in un genere particolare, quello dell'entrée, eminentemente irregolare nel realizzare la fusione di caratteri descrittivi con altri di 
amplificazione erudita. Lo studio delle strategie retoriche dei panegirici gesuitici d'inizio secolo rivela il passaggio da un legame tra potere e sacralità di tipo metonimico, durante il regno di Henri IV, ad uno metaforico all'epoca di Louis XIII, e segnala dunque l'evoluzione della visione del potere da un rapporto di vicinanza ad uno di equivalenza con Dio. È ancora in senso politico che Katherine IBBETT, Productive Perfection: the Trope of the River in Early Modern Political Writing, pp 44-57, indaga il concetto di perfezione applicato all'idea di fiume negli scritti politici di Giovanni Botero, Jean Silhon e Gabriel Naudé, per verificare come tale immagine diventi simbolo del perfetto classicismo.

2 Ad aprire la serie relativa alla perfezione in senso morale il contributo di Daniel MAHER Corrompre la perfection - de la Carte de Tendre aux Royaumes d'amour, pp. 58-77, dove le note cartografie di Mlle de Scudéry e di D'Aubignac vengono accostate ad altre meno celebri, quelle di Tristan l'Hermite e di Paul Tallemant, per constatare che soltanto la scrittura femminile propone l'ideale del perfetto amante, mentre le altre sembrano relegare tale perfezione in un non-luogo inaccessibile e inimitabile. È invece l'archetipo della moglie perfetta ad interessare Twyla MEDING, Lessons Too Old and Frocks Too Fine: Anachronistic Perfection and the Eclipse of Pastoral in Perrault's "Griselidis", pp. 78-110: la leggenda di Griselda, moglie umile e paziente, capace di superare le estenuanti prove escogitate dal principe consorte, circola nei secoli in Europa grazie all'intermediazione di Petrarca e Boccaccio, per giungere alla fine del XVII alla riscrittura di Perrault. L'A. individua l'Astrée tra le fonti implicite del favolista: Celadon, amante perfetto, e l'evidente anacronismo dei valori del mondo pastorale fungono da supporto alla nuova riscrittura della vicenda originaria, intrisa di nostalgia.

3 Emerge con forza dal saggio di Zahi zallouA (Im)-perfecting the Self: Montaigne's Pedagogical Ideal, pp. 111-126, quale sia l'ideale della perfezione umana in Montaigne: se Erasmo e Budé la considerano raggiungibile attraverso gli studi classici, l'analisi degli Essais rivela come Montaigne sparigli le carte, considerando come obiettivo del percorso di formazione umana l'idea di imperfezione. Rimane nell'ambito della scrittura moralistica il saggio di Karolyn WATERSON, contre-modèles de perfection dans "Les Caractères" de La Bruyère, pp. 127-155: attraverso una lettura intratestuale l'A. si propone di dimostrare come l'idealismo di La Bruyère attenga ai suoi contromodelli, e come questi si strutturino nell'immagine universale del tipo ideale.

4 I problemi della perfezione in relazione all'estetica teatrale sono indagati nei due saggi di Judd D. HUBERT, Corneille's Theatrical Approach to Perfection in "Sophonisbe", pp. 156-168, e Helen L. HARRISON, Corneille and Tragic Perfection: Rewriting "Oedipus", pp. 169-184. Il primo autore isola il personaggio di Sofonisba all'interno del paradigma eroico corneliano, verificandone il funzionamento teatrale nel sistema dei personaggi, per indicare come la perfezione venga qui raggiunta attraverso la rappresentazione del suicidio. Il secondo invece analizza prima il concetto di perfezione negli scritti teorici di Corneille, per poi verificarne il funzionamento nell'Oedipe, dove l'estetica teatrale si configura come riflesso del programma politico. Infine, Erec R. косн, Perfect Pitch: Sound, Aurality, and Rhetoric from Marin Mersenne's "Harmonie universelle" to Bernard Lamy's "La Rhetorique, ou l'art de parler", pp. 170-185, studia i trattati retorici alla luce dei nuovi trattati fisiologici, quando le caratteristiche fisiche della voce umana cominciano ad essere indagate e diventano dunque elemento aggiuntivo di efficacia dell'elocutio, contribuendo alla perfezione della persuasione retorica. 
5 Tra le qualità di questo volume multilingue rileviamo l'apertura alla prospettiva comparata, ad approcci metodologici diversi e ai lavori di giovani studiosi: alcuni contributi, e in particolare quelli di Hogg, Frappier, Koch, si distinguono per novità e originalità. 